\title{
Resection of primary lung cancer with incidental pleural seeding: Seeds of change or reap what you sow?
}

\author{
Jules Lin, MD
}

\footnotetext{
From the Section of Thoracic Surgery, Department of Surgery, University of Michigan Medical Center, Ann Arbor, Mich.

Disclosures: Author has nothing to disclose with regard to commercial support.

Received for publication Oct 29, 2017; accepted for publication Oct 30, 2017; available ahead of print Nov 29, 2017.

Address for reprints: Jules Lin, MD, Section of Thoracic Surgery, 1500 E Medical Center Dr, 2120TC/5344, Ann Arbor, MI 48109-5344 (E-mail: juleslin@umich.edu).

J Thorac Cardiovasc Surg 2018;155:1250-1

$0022-5223 / \$ 36.00$

Copyright $(2) 2017$ by The American Association for Thoracic Surgery

https://doi.org/10.1016/j.jtcvs.2017.10.123
}

Malignant pleural disease is generally considered a contraindication to lung cancer resection and has a 5-year survival of only $2 \%$. With modern imaging, however, incidentally found pleural disease may not be as extensive, and resection of the primary tumor may increase survival by reducing tumor burden for adjuvant chemotherapy. Studies evaluating pleural lavage have found microscopic pleural disease at the time of resection in $5.8 \%{ }^{1}$ In this issue of the Journal, $\mathrm{Li}$ and colleagues ${ }^{2}$ report improved survival after resection of the primary tumor in a retrospective study of 43 patients and argue that their results provide a seed of change for current practice.

A meta-analysis of 9 studies including 861 patients with incidental pleural disease by $\mathrm{Xu}$ and associates ${ }^{3}$ found a significant survival benefit with resection of the primary lung cancer. In contrast, Fiorelli and Santini ${ }^{4}$ evaluated 8 studies, including 4 from the meta-analysis by $\mathrm{Xu}$ and associates, ${ }^{3}$ and concluded the evidence was not strong enough to support resection of the primary tumor. Although Sawabata and colleagues ${ }^{5}$ found no benefit with resection in 43 patients, none received adjuvant chemotherapy, which could be important in treating any remaining disease.

The study of $\mathrm{Li}$ and colleagues ${ }^{2}$ adds to knowledge in this area, but there are several limitations. The tumor resection group had a lower $\mathrm{T}$ stage and more limited pleural disease $(13.3 \%$ vs $0 \%)$ than the group whose surgery did not include resection. These differences may have influenced the surgeon's decision making and thus may have biased the results, favoring increased survival in the resection group. There was also variability in treatment between pleurectomy and isolated resection of pleural nodules, and more patients in the resection group underwent neoadjuvant treatment $(23.3 \%$ vs $7 \%)$.

Patients may have had their disease understaged, because only $50 \%$ underwent a positron emission tomographic scan, and 10 of 30 patients had their disease upstaged from N0 to $\mathrm{N} 1$ or N2. The pathologic staging was also incomplete. Mediastinal lymph node dissection was performed in only 9 of 16 patients $(56.3 \%)$ who underwent

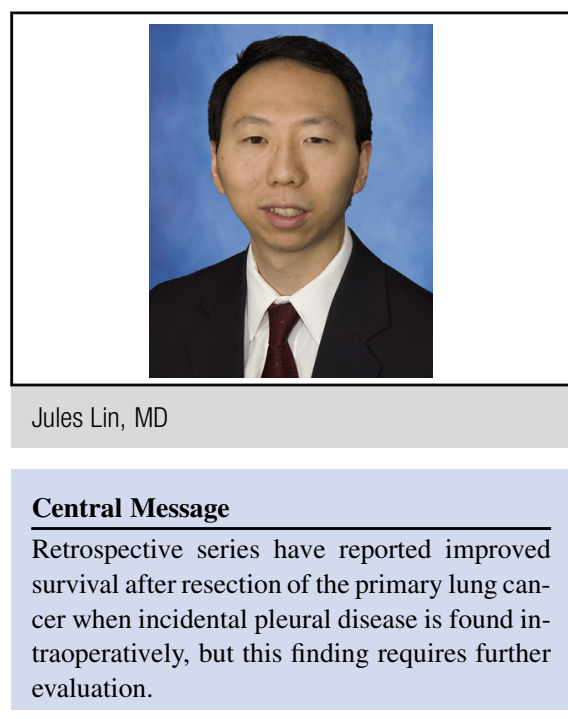

See Article page 1238. wedge resection, which could explain why $\mathrm{Li}$ and colleagues $^{2}$ found no difference between N0 and N1 or $\mathrm{N} 2$ disease. In other studies, nodal stage has been significantly associated with survival in patients undergoing resection. ${ }^{3,6}$

The patient population, as in most other studies, was almost uniformly Asian. EGFR mutations were present in $58.1 \%$ of tumors, which is a higher prevalence than in other parts of the world, and $67.4 \%$ of patients received adjuvant therapy with tyrosine kinase inhibitors. How this affected the results and whether these findings are applicable to other patient populations must also be considered.

Although the study is thought-provoking, caution must be taken in interpreting the results because of its small sample size, Asian population, selection bias, and potential understaging. Other studies have also been limited by variability in the extent of pulmonary and pleural resection, as well as the inconsistent use of adjuvant and pleural chemotherapy, and there are not enough data to change current practice. Larger, prospective studies are needed, with standard treatment and staging protocols and clear definitions of the extent of pleural disease, before deciding that the results are seeds of change - and to ensure that you do not just reap what you sow.

\section{References}

1. Lim E, Clough R, Goldstraw P, Edmonds L, Aokage K, Yoshida J, et al; International Pleural Lavage Cytology Collaborators. Impact of positive pleural lavage 
cytology on survival in patients having lung resection for non-small-cell lung cancer: an international individual patient data meta-analysis. J Thorac Cardiovasc Surg. 2010;139:1441-6.

2. Li C, Kuo SW, Hsu HH, Lin MW, Chen JS. Lung adenocarcinoma with intraoperatively diagnosed pleural seeding: Is main tumor resection beneficial for prognosis? J Thorac Cardiovasc Surg. 2018:155:1238-49.

3. Xu Y, Chen N, Wang Z, Zhang Y, Mei J, Liu C, et al. Should primary tumor be resected for non-small cell lung cancer with malignant pleural disease unexpectedly found during operation? - a systemic review and meta-analysis. J Thorac Dis. 2016;8:2843-52.
4. Fiorelli A, Santini M. In lung cancer patients where a malignant pleural effusion is found at operation could resection ever still be justified? Interact Cardiovasc Thorac Surg. 2013;17:407-12.

5. Sawabata N, Matsumura A, Motohiro A, Osaka Y, Gennga K, Fukai S, et al; Japanese National Chest Hospital Study group for Lung Cancer. Malignant minor pleural effusion detected on thoracotomy for patients with non-small cell lung cancer: is tumor resection beneficial for prognosis? Ann Thorac Surg. 2002;73:412-5. 6. Ichinose Y, Tsuchiya R, Koike T, Kuwahara O, Nakagawa K, Yamato Y, et al; Japan Clinical Oncology Group. The prognosis of patients with non-small cell lung cancer found to have carcinomatous pleuritis at thoracotomy. Surg Today. 2000;30:1062-6. 